\title{
The effects of an omega-3 fatty acid enriched supplement on physical performance in older women - a randomised double-blind placebo controlled study
}

\author{
S. C. Dyall ${ }^{1}$, A. Carlisle ${ }^{1}$, E. L. Gibson ${ }^{2}$ and S. Strike ${ }^{1}$ \\ ${ }^{1}$ Department of Life Sciences, University of Roehampton, London SW15 4JD UK and ${ }^{2}$ Department of Psychology, \\ University of Roehampton, London SW15 4JD UK
}

Lower intake of the omega-3 fatty acids, eicosapentaenoic (EPA) and docosahexaenoic (DHA) acid is associated with poorer functional mobility and supplementation improves walking speed in older females ${ }^{(1)}$. Slower gait can decrease quality of life and is a predictor of all-cause mortality ${ }^{(2)}$. The present study assessed the effects of a high dose DHA supplement on walking speed and lower body strength and power in older females.

A stratified block randomisation design was used, matching frailty phenotypes between treatment groups ${ }^{(3)}$. Participants received either Efalex Active 50+ (1 g DHA, $160 \mathrm{mg}$ EPA, $240 \mathrm{mg}$ gingko biloba, $60 \mathrm{mg}$ phosphatidylserine, $20 \mathrm{mg}$ d-alpha tocopherol, $1 \mathrm{mg}$ folic acid and $20 \mu \mathrm{g}$ vitamin $\mathrm{B} 12$ per day, $\mathrm{N}=15)$, or placebo $(\mathrm{N}=12)$ for six months. Participants undertook a detailed biomechanical analysis of self-selected habitual and fast walking and vertical jump height (VJH) at the start and end of the study. Blood DHA levels were also measured in non-fasted subjects by pin prick analysis (expressed as \% of total fatty acids) ${ }^{(4)}$.

\begin{tabular}{|c|c|c|c|c|c|c|c|c|c|c|}
\hline \multirow[b]{2}{*}{ Group } & \multirow[b]{2}{*}{ PV } & \multicolumn{4}{|c|}{ Fast walk speed (\% changes) } & \multirow[b]{2}{*}{ PV } & \multicolumn{4}{|c|}{ VJH ( $\%$ change $)$} \\
\hline & & $\mathrm{RC}$ & $95 \% \mathrm{CI}$ & $\mathrm{P}$ value & $\mathrm{SC}$ & & $\overline{\mathrm{RC}}$ & $95 \% \mathrm{CI}$ & $\mathrm{P}$ value & $\mathrm{SC}$ \\
\hline \multirow[t]{2}{*}{ Placebo } & DHA & $0 \cdot 4$ & $0 \cdot 1,0 \cdot 7$ & 0.01 & 0.7 & \multirow[t]{2}{*}{ DHA } & \multirow[t]{2}{*}{$0 \cdot 7$} & \multirow[t]{2}{*}{$0 \cdot 3,1 \cdot 2$} & \multirow[t]{2}{*}{$0 \cdot 004$} & \multirow[t]{2}{*}{$0 \cdot 8$} \\
\hline & BMI & $-1 \cdot 3$ & $-2 \cdot 3,10 \cdot 2$ & 0.02 & $-0 \cdot 5$ & & & & & \\
\hline \multirow[t]{2}{*}{ Active } & DHA & $0 \cdot 4$ & $0 \cdot 0,0 \cdot 6$ & 0.03 & $0 \cdot 5$ & \multirow[t]{2}{*}{ DHA } & \multirow[t]{2}{*}{$0 \cdot 5$} & \multirow[t]{2}{*}{$0 \cdot 0,1 \cdot 0$} & \multirow[t]{2}{*}{0.04} & \multirow[t]{2}{*}{$0 \cdot 5$} \\
\hline & Age & $-0 \cdot 6$ & $-1 \cdot 1,10 \cdot 2$ & $0 \cdot 01$ & $-0 \cdot 6$ & & & & & \\
\hline
\end{tabular}

Abbreviations: PV, predictor variable; RC, regression coefficient; SC, standardised coefficient

Supplementation resulted in significantly higher blood DHA levels compared to the placebo group (mean $3 \cdot 5 \%$ (SD $1 \cdot 3 \%$ ) vs $3 \cdot 3 \%$ $(1 \cdot 0 \%)$, respectively, $\mathrm{F}(1,26)=5 \cdot 9, \mathrm{P}=0.02)$ adjusted for baseline values $(3 \cdot 0 \%(1 \cdot 1 \%) \mathrm{vs} .3 \cdot 26 \%(1 \cdot 1 \%)$, respectively). Since individuals respond differently to omega-3 fatty acid supplementation ${ }^{(5)}$, multiple linear regression models were used to analyse the relationship between $\%$ changes in DHA blood status and \% changes in physical performance in both groups compared to baseline values. Also included in the models were age, BMI, self-reported physical activity (PASE) ${ }^{(6)}$ and grip strength. Changes in DHA were significantly associated with both fast walking speed and VJH (Table), but not self-selected habitual walking speed. BMI and age were also significant contributory factors for fast walking speed in placebo and active treatment groups, respectively (Table); however, there were no significant effects for grip strength or PASE.

Short-term supplementation with an enriched DHA supplement was associated with significant increases in blood DHA content and there were significant positive relationships between increased DHA status and improved fast walking speed and VJH. Interestingly, there were no significant differences in these effects between the groups, suggesting the effects were mediated via changes in DHA, rather than the other components in the treatment. Further work will seek to explore the nature of this relationship. However, these effects were seen in the absence of an anabolic stimulus, suggesting a potential therapeutic role for DHA in improving functional mobility and power in the older adult.

This work was supported by Efamol Ltd/Wassen Intl Ltd.

1. Hutchins-Wiese HL, Kleppinger A, Annis K, et al. (2013). J Nutr Health Aging. 17, 76-80.

2. Cummings SR, Studenski S, Ferrucci L. (2014). JAMA. 311, 2061-2.

3. Fried LP, Tangen CM, Walston J, et al. (2001). J Gerontol A Biol Sci Med Sci. 56, M146-56.

4. Metherel AH, Buzikievich LM, Charkhzarin P, et al. (2013). Nutr Res. 32, 547-56.

5. Plourde M, Vohl MC, Vandal M, et al. (2009). Br J Nutr. 102, 1121-4.

6. Washburn RA, Smith KW, Jette AM, et al. (1993). J Clin Epidemiol. 46, 153-62. 